\title{
RELATIVE QUALITY OF THE MAJOR FOREST ASSOCIATIONS OF THE SOUTHERN B.C. INTERIOR FOR GROWTH OF LODGEPOLE PINE, ENGELMANN SPRUCE, DOUGLAS-FIR AND ALPINE FIR ${ }^{2}$
}

By WALTER STANEK ${ }^{2}$

\begin{abstract}
Height growth of lodgepole pine, Engelmann spruce, Douglas-fir and alpine fir was investigated in the Douglas-fir and Engelmann Spruce-Alpine Fir Zones of the Interior of British Columbia. In the same forest association each species has a characteristic site index at the age of 100 years (S1/100). Regression equations were calculated for predicting SI/100 of several species in different associations. Regression equations were also developed for estimating SI/100 of Engelmann spruce, Douglas-fir and alpine fir from known SI/100 of lodgepole pine. The latter species was selected because of its common occurrence in the two zones. In addition regression equation was calculated for predicting SI/100 of lodgepole pine from known SI/100 of Engelmann spruce. All regression equations apply to naturally established stands in the study area.
\end{abstract}

\section{INTRODUCTION}

Relative height growth of several tree species in similar forest associations (types) of the Interior Douglas-fir (IDF) and Engelmann Spruce-Alpine Fir (ES-AF) Zones (Krajina, 1964) was studied. Species involved were lodgepole pine, Pinus contorta Dougl., Engelmann spruce, Picea engelmannii Parry, Douglas-fir, Pseudotsuga menziesii (Mirb.) Franco, and alpine fir, Albies lasiocarpa (Hook.) Nutt. (scientific names according to Little, 1953).

From 127 forest stands Stanek (1966) took height, and diameter at breast height measurements and counted the total age of several hundred trees and saplings of the four species. Statistical analysis of the data was made according to a programme supplied by Dr. A. Kozak of the Faculty of Forestry, University of British Columbia on the IBM 7040 electronic computer.

This study attempts to give relationships of several species to each other with regard to height growth. The regression equations make it possible to predict the height growth of one species from the height growth of another species, or from the known forest association of a certain area.

\footnotetext{
${ }^{1}$ Research Note No. 58. U.B.C. Faculty of Forestry. This paper is based on part of a Ph.D. thesis submitted to the University of British Columbia.

${ }^{2}$ Research Officer, Canada Dept. of Forestry, Sillery, P.Q.
} 


\section{LITERATURE REVIEW}

The relationships of various species with regard to their site index on the same sites were investigated by Foster (1959) who compared the performance of white pine, Pinus strobus L., and red maple, Acer rubrum L., in New York, western Massachusetts and Connecticut. Olson and Della-Bianca (1959) compared the site index of several hardwoods. Both found significant correlations of the site index between the species.

Henninger (1962) compared the site indices of two pines in Tennessee. The differences were significant and in fifty years on the same site more lumber was obtained from Virginia pine, Pinus virginiana Mill. in contrast to shortleaf pine, P. echinata Mill. Doolittle (1958) compared the site indices of ten species in the southern Appalachians and has shown that when one site index is known, the site indices of all other species can be predicted.

Deitschman and Green (1965) established relationships between the site index of western white pine, Pinus monticola Dougl. and the tree height of several species. They suggested equations for making management decisions. Their source data were taken from plots in unmanaged second growth stands in which the density and species composition have undoubtedly affected the height growth relations differently than they would on intensively managed plots.

Bazjak (1960) and Smith and Bajzak (1961) estimated average site indices of several species directly on aerial photos and developed regression equations for estimating the average site index for several species.

The results of all the cited authors show that the site indices of several species are closely correlated.

\section{Forest Associations or Types of The Study AREA}

The writer intended to establish a relationship between the forest associations and the growth of the four species. The forest associations of the interior of British Columbia were described by Thrupp (in Ilvessalo, 1929), Ilvessalo (1929), Kujala (1945), Krajina (in Forestry Handbook, 1959) and Illingworth and Arlidge (1965). Their work was reviewed and the associations occurring in the study area were defined by Stanek (1966).

For calculation of regression equations the associations were assessed according to their potential values for growing forest tree species. In Table 1 are shown the names of the associations, the SI/100 ranges (i.e. site index at the age of 100 years determined according to curves in B.C. Forest Service, 1964), observed as well as the derived code values, and productivity rating. The code was derived from comparisons of the average maximal height of dominant and codominant trees, basal area and volume of the forest stands and the general environmental conditions of the individual associations. The productivity classes are equivalent to the site index classes recognized by the B.C. Forest Service (1964). The smallest code value was assigned to the association of the lowest productivity class, the highest to the association of the highest productivity class.

Few data were available in the Creek Bottom and none in the Oplopanax associations. With additional data the regression in that range would perhaps change. 


\section{Multiple Correlation of Association and Site Indices}

The relationship of the associations and the SI/100 of the species Engelmann spruce, lodgepole pine, Douglas-fir and alpine fir, each with 86 observations, was evaluated in a multiple correlation analysis. Basic data were not included here. However, Table 1 shows the observed ranges of SI/100 which a species can assume in the same association. In several of the associations, individual species were not found. These species were located either nearby or in similar associations elsewhere. Values thus obtained served as substitutes in the computer programme.

The results have shown that all variables are highly significantly correlated (at $1 \%$ level) and that any one can be approximated from the other. The results shown in Fig. 1 confirm the relationships of the species indicated in Table 1 . The regression equations obtained are as follows, $(y=S I / 100 ; x=$ association in code):

$$
\begin{aligned}
& \mathrm{ES}, \mathrm{y}=30.96+0.94 \mathrm{x} ; \mathrm{r}=0.91 ; \mathrm{SE}_{\mathrm{E}}= \pm 13.3 \mathrm{ft} .(\mathrm{SI} / 100) \\
& \mathrm{LP}, \mathrm{y}=48.89+0.59 \mathrm{x} ; \mathrm{r}=0.86 ; \mathrm{SE}_{\mathrm{E}}= \pm 10.6 \mathrm{ft} .(\mathrm{SI} / 100) \\
& \mathrm{DF}, \mathrm{y}=46.37+0.75 \mathrm{x} ; \mathrm{r}=0.89 ; \mathrm{SE}_{\mathrm{E}}= \pm 11.8 \mathrm{ft} .(\mathrm{SI} / 100) \\
& \mathrm{AF}, \mathrm{y}=25.28+0.82 \mathrm{x} ; \mathrm{r}=0.89 ; \mathrm{SE}_{\mathrm{E}}= \pm 13.1 \mathrm{ft} .(\mathrm{SI} / 100)
\end{aligned}
$$

The regression lines of lodgepole pine and Engelmann spruce crossed in the range of the medium and good productivity class ( $\mathrm{Pa}, \mathrm{C}, \mathrm{VM}, \mathrm{VV}$ associations). This indicates that at the age of 100 years in associations of low and poor productivity classes, lodgepole pine outgrows Engelmann spruce in height; in the associations of the medium productivity class, both species reach similar heights at 100 years of age (Engelmann spruce more so on relatively moist sites); and in the associations of the good and best productivity class, at the age of 100 years Engelmann spruce is higher than lodgepole pine. Douglas-fir is best-growing at the age of 100 years in all but the associations of the low to poor productivity ranges, where it just equals lodgepole pine.

In the creek bottom associations on seepage sites, with good supply of moisture and nutrients, Douglas fir and Engelmann spruce achieve excellent height growth followed by alpine fir and lodgepole pine.

It is important to add, that with few exceptions, all alpine firs were the youngest trees in the stands investigated and were therefore exposed to more shading than lodgepole pine, Douglas-fir or perhaps even Engelmann spruce. This is possibly why the regression line of alpine fir lies below all others; occasionally excellent alpine firs were found which surpassed in growth the level generally found in this species.

It must be pointed out that the data were collected in unmanaged, naturally established stands in which particularly the successional trends affected the height growth. The resulting regression equations therefore apply in naturally established stands under similar conditions as exist in the British Columbia Interior.

The multiple regression analysis of association on SI/100 of ES, LP, DF and $\mathrm{AF}$ has shown that $85.5 \%$ of the variation of association is accounted for by the SI/100 of the four species. After elimination of the least significant 


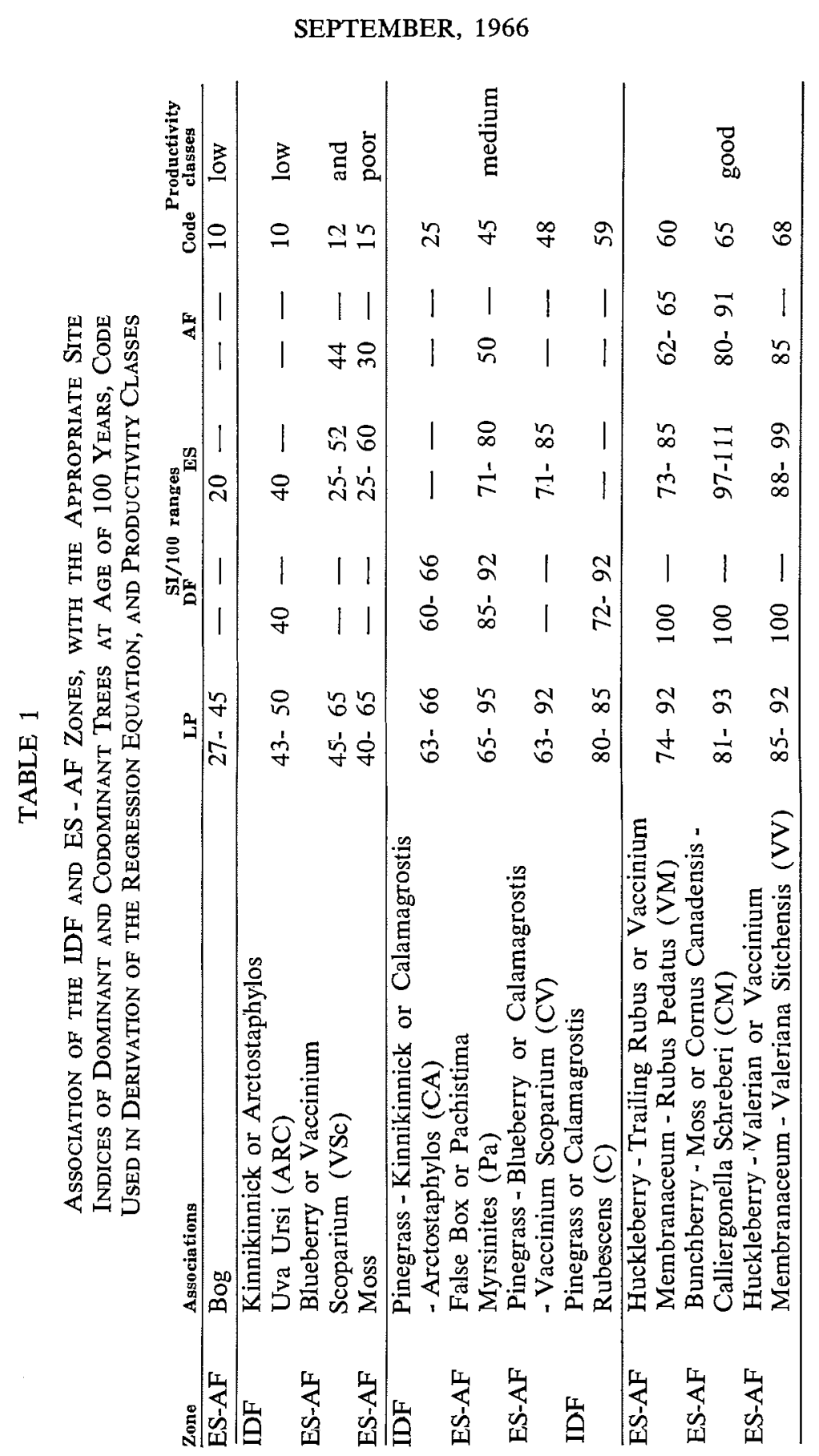




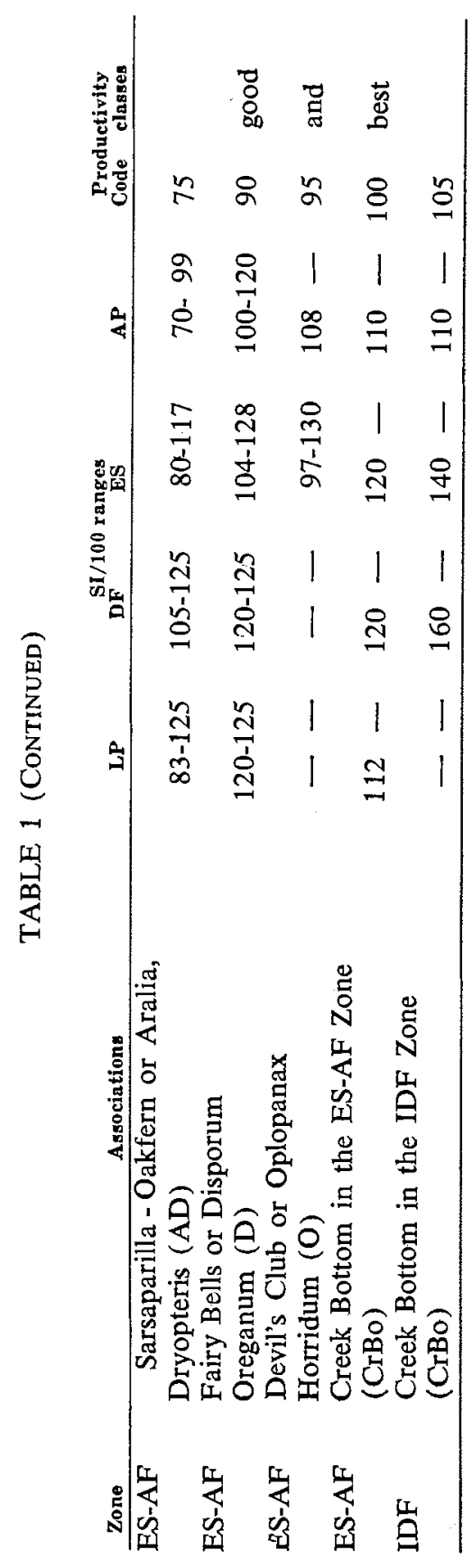




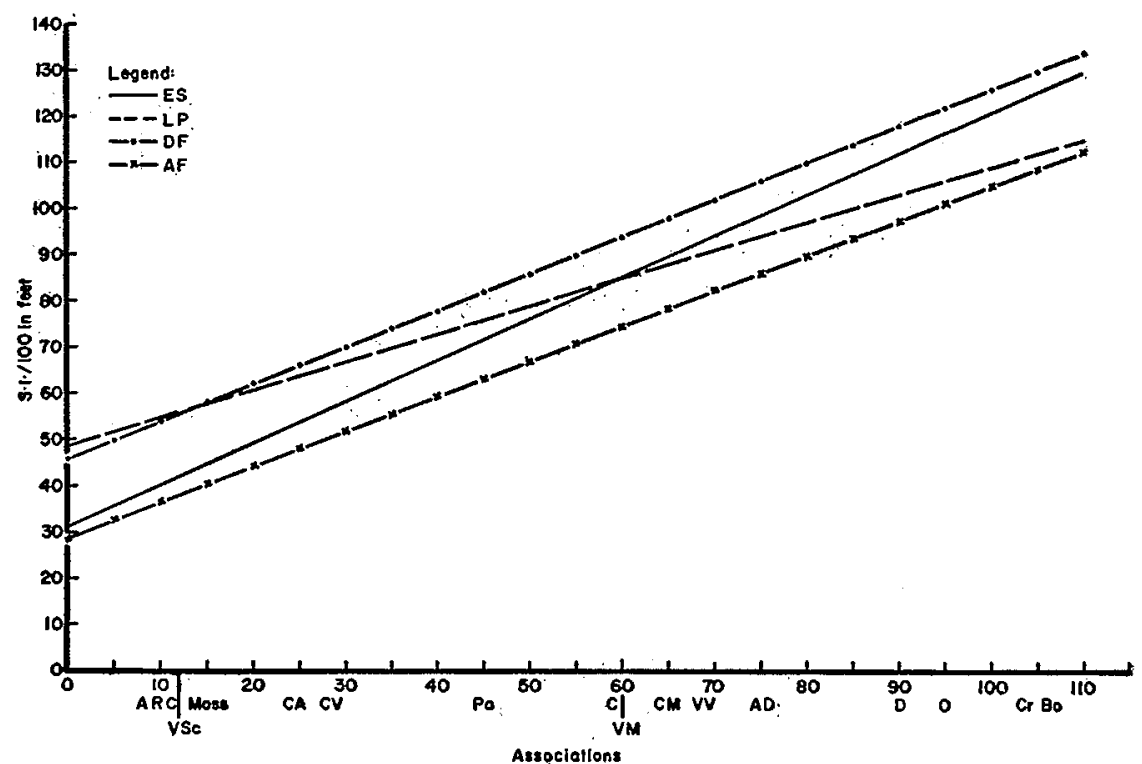

FIGURE 1. Comparison of regression lines of site index at the age of 100 years (SI/100=y) on association (code and names $=\mathrm{X}$ ) of $\mathrm{ES}, \mathrm{LP}, \mathrm{DF}$, and $\mathrm{AF}$.

variables, SI/100 of ES alone accounted for $82.4 \%$ of the variation and is therefore the most important determining variable. The remaining SI/ 100 of LP, DF, and AF added only little to the regression equation. The derived equation of association based on SI/100 of all species is:

$$
\begin{aligned}
\text { association }= & -30.06+0.31 \mathrm{SI} / 100 \text { of } \mathrm{ES}-4.50 \mathrm{SI} / 100 \text { of } \mathrm{LP}+ \\
& 0.42 \mathrm{SI} / 100 \text { of } \mathrm{DF}+0.27 \mathrm{SI} / 100 \text { of } \mathrm{AF} ; \\
& \mathrm{R}=0.92 ; \mathrm{SE}_{\mathrm{E}}= \pm 11.9 \text { Code values; }
\end{aligned}
$$

Calculated with ES alone,

$$
\text { association }=-17.97+0.88 \mathrm{SI} / 100 \text { of } \mathrm{ES} ; \mathrm{r}=0.91 ;
$$

If analyzed in simple correlations, the SI/100 of the species on association shows, that ES accounts for $82.4 \%$ (as above), DF for $79 \%, \mathrm{AL}$ for $79 \%$ and LP for $74.8 \%$ of the variation. This defines ES as the species safest to use in determination of the association. However, in many areas no species other than LP occurs in mature stands. Also LP is an ubiquitous species in B.C. and covers a wider range of habitats than the remaining three. Therefore, the equation for determining the association using SI/100 of LP is given.

$$
\text { association }=\frac{-48.44+1.26 \mathrm{SI} / 100 \text { of } \mathrm{LP} ; \mathrm{r}=0.86 ;}{\mathrm{SE}_{\mathrm{E}}= \pm 15.5 \text { Code values }}
$$

and the equations for determination of the SI/100 of ES, IDF and AL when $\mathrm{SI} / 100$ of LP is known are:

$$
\begin{gathered}
\mathrm{SI} / 100 \text { of } \mathrm{ES}=-30.07+1.38 \mathrm{SI} / 100 \text { of } \mathrm{LP} ; \mathrm{r}=0.91 \\
\mathrm{SE}_{\mathrm{E}}= \pm 12.8 \mathrm{ft} \text {; }
\end{gathered}
$$




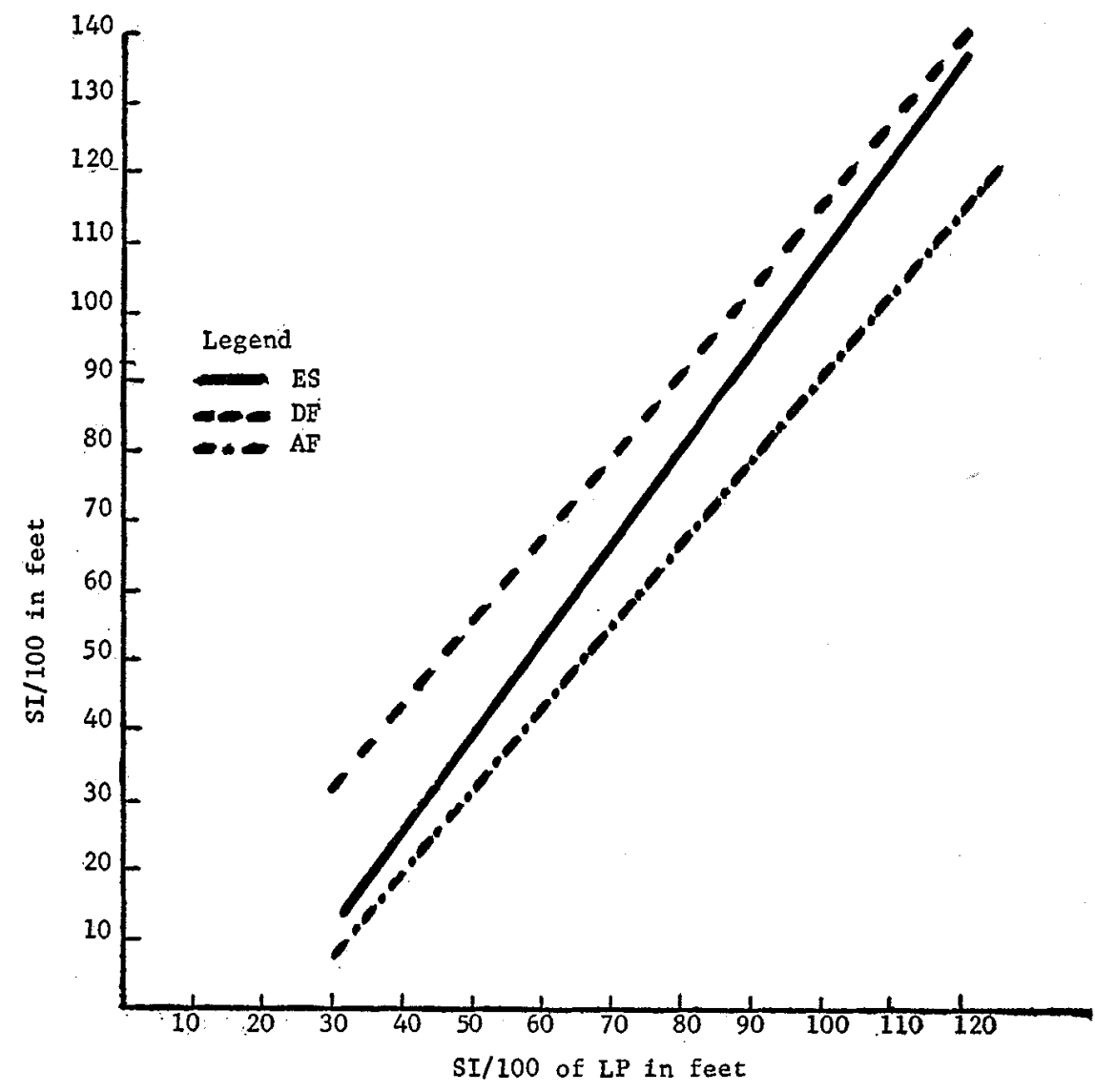

FIGURE 2, Regression lines of site index at 100 years of ES, DF, and AF on SI/100 of LP.

$$
\begin{gathered}
\text { SI } / 100 \text { of DF }=-2.23+1.21 \mathrm{SI} / 100 \text { of LP; } r=0.89 \\
\text { SI } 100 \text { of AF = }-27.93+1.21 \mathrm{fI} / 100 \text { of LP; } r=0.89 ; \\
\text { SE }_{\mathrm{E}}= \pm 12.9 \mathrm{ft} .
\end{gathered}
$$

The range covered by these equations is approximately, from SI/100 of LP of $40 \mathrm{ft}$. to $120 \mathrm{ft}$. The derived regression lines are shown in Fig. 2.

This study indicated that Douglas-fir has the best height growth of all the species investigated in almost all associations. This fact merits further investigation of the growth performance and possible volume production of this species in the different associations. 
The results of this study suggest also that the SI/100 of Engelmann spruce is better than that of lodgepole pine in associations of good and best productivity. However, Stanek (1966) concluded that under intensive management with relatively short rotation periods, lodgepole pine could be favoured over spruce in much of the Interior of B.C., because of its faster juvenile growth in diameter at breast height and higher volume production per acre.

\section{BIBLIOGRAPHY}

BAJZAK, D. 1960. An evaluation of site quality from aerial photographs of the University of British Columbia Research Forest, Haney, B.C. U.B.C. Faculty of Forestry, M.F. Thesis, 113 pp.

B.C. FOREST SERVICE. 1964. Field Pocket Manual. Forest Surveys and Inventory Division, 83 pp.

DEITSCHMAN, G. H. and A. W. GREEN. 1965. Relations between western white pine site index and tree height of several associated species. USDA, For. Serv., Intermountain For. and Range Exp. Sta., Ogden, Utah, Res. Pap. INT-22, 28 pp.

DOOLITTLE, W. T. 1958. Site index comparisons for several forest species in the Southern Appalachians. Proc. Soil Sci. Soc. of Amer. 22(5):455-8.

FORESTRY HANDBOOK. 1959. Forestry Handbook for British Columbia. U.B.C. Forest Club. 2nd Ed. 800 pp.

FOSTER, R. W. 1959. Relations between site indexes of eastern white pine and red maple. For. Sci. 5:279-291.

HENNINGER, C. M. 1962. Site index of two pines on the Cumberland Plateau in Tennessee. J. Soil Water Conserv. 17(4):175-6.

ILLINGWORTH, K. and J. W. C. ARLIDGE. 1960. Interim report on some forest site types in lodgepole pine and spruce-alpine fir stands. Dept. of Lands \& Forests, B.C. For. Serv. Res. Note No. 35, 44 pp.

ILVESSALO, Y. 1929. Notes on some forest site types in North America. Acta Forestalia Fennica, 34 (39):1-111.

KRAJINA, V. J. 1964. Ecology of the forests of the Pacific Northwest. Dept. Biol, and Bot., U.B.C., Vancouver, B.C. p. 71-87.

KUJALA, V. 1945. Waldvegetationsuntersuchungen in Kanada (Forest vegetation investigation in Canada). Acad. Scient. Fennica, Series A. IV. Biblogica 7:434pp.

LACATE, D. S., P. N. SPROUT, J. W. C. ARLIDGE and A. MOSS. 1965. Forest land classification and interpretations for management in the spruce working circle, tree farm license No. 9, Okanagan Valley, B.C. B.C. Dept. Agr., Soil Surv. Div., Kelowna, B.C., Interim Rep., 39 pp.

LITTLE, E. L. Jr. 1953. Check list of native and naturalized trees of the United States (including Alaska). USDA, Agr. Handb. No. 41, For. Serv., Washington, D.C., 263 pp.

MITCHELL, K. J. 1963. Variations in the growth of Engelmann spruce in a valley in the southern interior of British Columbia. Can. Dept. For., For. Res. Br., B.C. District, Prog. Rep. 63-BC-10, 14 PP.

OLSON, D. F. Jr, and DELLA BIANCA, L. 1959. Site index comparisons for several tree species in the Virginia - Carolina Piedmont. USDA, For. Serv., southeast For. Exp. Sta., Asheville, North Carolina, Sta. Pap. 104, 9 pp.

STANEK, W. 1966. Occurrence, growth, and relative value of lodgepole pine and Engelmann spruce in the Interior of British Columbia. Ph.D. thesis, U.B.C. Fac. of For., 267 pp.

SMITH, J. H. G. and D. BAJZAK. 1961. Photo interpretation provides a good estimate of site index of fir, hemlock and cedar. Journ. For.. $59(4): 261-4$.

THRUPP, A. C. 1927. Scientific seed collection. For. Chron. 3(2): 